
presenting with complex components: A case report with literature review

\title{
Multimodality imaging toward diagnosis of an intraventricular bronchogenic cyst presenting with complex components: A case report with literature review
}

\author{
Yang Chen ${ }^{1,2}$, Yinsu Zhu ${ }^{1}$, Yi Xu' ${ }^{1}$ Xiaoyue Zhou ${ }^{3}$, Xiaomei Zhu ${ }^{1 *}$ \\ 1. Department of Radiology, the first affiliated hospital Nanjing medical university, China \\ 2. Department of Radiology, Wuxi people's hospital, Nanjing medical university, China \\ 3. MR Collaboration, Siemens Healthineers, Shanghai, China
}

* Correspondence: Xiaomei Zhu, the first affiliated hospital Nanjing medical university, Guangzhou Road 300, 210029, China

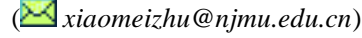

Radiology Case. 2022 Feb; 16(2):1-11 :: $\quad$ DOI: 10.3941/jrcr.v16i2.4109

\begin{abstract}
Cardiac bronchogenic cysts are rare lesions with very thin walls. We present a case of a 49-year-old man with intermittent chest pain and distress who was found to have a bronchogenic cyst in the right ventricle with complex tissue changes. The clinical manifestations, image findings, and differential diagnoses of bronchogenic cysts are discussed.
\end{abstract}

\section{CASE REPORT}

\section{CASE REPORT}

A 49-year-old man presented to a hospital with intermittent chest pain and distress for a month. Echocardiography revealed decreased left ventricular diastolic function and a mass in the right ventricle (RV). The patient was admitted for further treatment. The findings of physical examination were unremarkable. The results of routine blood examinations, cardiac biomarkers, and brain natriuretic peptide tests were normal. Transthoracic echocardiography (TTE) revealed presence of an oval mass $(3.6 \times 3.3 \mathrm{~cm})$ with heterogeneous echocardiographic changes in the RV (Figure 1). The mass lacked vascularity, as demonstrated by the color Doppler imaging (Figure 1). Cardiac computed tomography (CT) and magnetic resonance imaging (MRI) were performed before tumor resection.
A retrospective electrocardiogram-gated CT scan showed a round, well-circumscribed mass $(3.5 \times 3.4 \times 3.6 \mathrm{~cm})$ with heterogeneous attenuation attached to the free wall of the RV. In addition to the cystic changes, fatty and soft tissues along with patchy calcifications were observed within the intracardiac mass. The soft tissue of the mass demonstrated moderate enhancement, whereas cystic or fatty tissue showed no enhancement (Figure 2).

Cardiac MRI was performed to assess the characteristics of the right ventricular mass. The mass had well-defined borders with complex changes and was attached to the free wall of the $\mathrm{RV}$. The surface of the mass demonstrated hyperintense signals on T1-weighted (T1W) images and hypointense signals on fatsuppressed T2-weighted (FST2W) images. Long T1 and short $\mathrm{T} 2$ values were observed in the native T1- and T2-mapping, suggesting the presence of fatty tissue. The center of the mass 
was hyperintense on both T1W and FST2W images and displayed short $\mathrm{T} 1$ and long $\mathrm{T} 2$ values in native T1- and T2mapping, indicative of the presence of viscous cyst fluid (Figures 3 and 4). Rest myocardial perfusion imaging revealed that the periphery of the mass had continuous, progressively increasing enhancement following the intravenous administration of a gadolinium-based contrast agent (Movie I and II in the Supplementary Data). The mass showed prominent peripheral rim enhancements with a 10-min delay, which was also confirmed by a shortened T1 value detected with postenhanced T1-mapping. The left ventricle demonstrated abnormal patchy fibrosis, whereas no prominent fibrosis was detected in the RV (Figures 4 and 5). The size and systolic function of the right and left ventricles were within the normal range (Movie III in the Supplementary Data).

The patient underwent conventional median sternotomy to remove the tumor with aortic and bi-caval extracorporeal circulation. Cardiac arrest was induced by cold blood cardioplegia. The right atrium was opened, and a $3 \times 3 \mathrm{~cm}$ tumor with a pedicle on the free wall of the right ventricular outflow tract was identified through the tricuspid valve. Next, the right ventricular outflow tract was opened, and the tumor was completely exposed and resected. The resected cardiac mass contained a yellowish-white gelatinous fluid. The patient's postoperative course was uneventful, and he was discharged 7 days later.

Microscopically, a portion of the tumorous epithelium was ciliated and pseudostratified columnar epithelium (Figure 6) surrounded by smooth muscle could be seen. Moreover, fatty tissue and nodular calcifications were observed without cartilage. These histological findings were compatible with the diagnosis of a bronchogenic cyst.

Follow-up echocardiography at 1, 3, 6, and 12-months thereafter showed no apparent right ventricular abnormalities. During his first year of outpatient follow-up, the patient was asymptomatic without any evidence of recurrence.

\section{DISCUSSION}

\section{Etiology \& Demographics:}

Bronchogenic cysts are benign, congenital tumors that develop from the abnormal budding of primitive ventral foreguts during embryologic development of tracheobronchial trees. These cysts are commonly found in the mediastinum and lungs, and seldom occur inside the heart. The cardiac primordia are close to the foregut, where abnormal buds rarely migrate to the myocardium and become the source of intracardiac cysts [1].

Intracardiac bronchogenic cysts are extremely rare, a $12 \%$ to $18 \%$ prevalence being documented among all primary intracardiac masses. The right side of the heart is the most frequent position [2]. These cysts have no age predilection and are generally detected incidentally, usually in the second to fourth decade. Though no studies have reported cases of malignant transformation, Park et al. demonstrated a rapidly growing bronchogenic cyst in the right atrium [3].

\section{Clinical \& Imaging findings:}

Intracardiac bronchogenic cysts are mostly asymptomatic; at times, causing a variety of symptoms such as chest pain, shortness of breath, and arrhythmias depending on the location and size of the cysts and compression of the adjacent structure. Immunohistochemistry of the ciliated columnar epithelium revealed that these cysts are positive for cytokeratin 7 and thyroid transcription factor- 1 and negative for cytokeratin 20 and calretinin [4].

Transthoracic echocardiography is usually the preferred detection method for cardiac tumors, as it provides accurate details of tumor location, size, mobility, point of attachment, and hemodynamic parameters. Intracardiac bronchogenic cysts are well-defined, thin-walled masses containing simple fluid, demonstrating homogeneous, hypoechoic masses on TTE. However, echocardiography is an operator-dependent modality that can affect the diagnostic accuracy. In contrast, cardiac CT shows the relationship between tumors and surrounding structures, as well as reveals the tumor characteristics. Bronchogenic cysts usually appear as round, homogeneous, non-enhanced lesions with very thin walls and lower densities [5]. Occasionally, heterogeneous bronchogenic cysts have been reported with high densities, containing calcium, fat, or other protein contents. Ma et al. reported cases of bronchogenic cyst with specific lipomatous tissue changes detected by CT and MRI images [6,7]. For heterogeneous bronchogenic cysts, cardiac CT and MRI are recommended to visualize the complicated features of the mass [8].

Cardiac magnetic resonance (CMR) provides significant morphological information as it involves multiple imaging modalities. It is the preferred method for the comprehensive assessment of cardiac tumors which can offer important treatment guidance [9]. Generally, the MRI signal intensity of a bronchogenic cyst depends on its internal composition. These cysts are hypointense on T1W images, hyperintense on T2W images, and have no overt enhancement following application of contrast materials. However, a few bronchogenic cysts have been reported to be hyperintense on T1W images, suggesting the presence of blood, proteinaceous, or viscous components $[8,10,11]$.

To our knowledge, this is the first report of an intracardiac bronchogenic cyst with complicated tissue components detected by different imaging modalities, including echocardiography, CT, and MRI.

\section{Treatment \& prognosis:}

Symptomatic cysts should be excised; however, patients with bronchogenic cysts are primarily asymptomatic, and their management is controversial. The recommended treatment for asymptomatic cysts is surgical resection because cyst progression has been associated with potential complications, such as infection, hemorrhage, and neoplasia. A study reported that patients with asymptomatic cysts have fewer postoperative complication than those with symptomatic cysts [12]. Two main surgical approaches are considered for treatment: video- 
assisted thoracoscopic surgery and thoracotomy. Though the former is more commonly used, the latter is applied to complicated cysts that require complete resection.

\section{Differential Diagnosis:}

Cardiac bronchogenic cysts are rare, and the rate of misdiagnosis is high. Differential diagnoses for cardiac tumors include thrombosis, myxoma, papillary fibroelastoma, lymphangioma, metastasis, and cardiac echinococcosis.

\section{Thrombosis}

Cardiac thrombosis, usually located in the left atrium and atrial appendage, occurs in hypercoagulable states. It often has a multiform morphology, smooth surface, and poor mobility. Two types of thrombi are reported in the right heart: 1) deep venous thrombi that temporarily break into the right atrium or ventricle, and 2) mural thrombi that are immobile. Mural thrombosis has a broad-based attachment to the heart wall, whereas mobile thrombosis has a thin stalk or no attachment point [13]. Thrombi appear as hyperechoic lesions on TTE. Thrombi are hypodense on CT images and hypointense on T1W and $\mathrm{T} 2 \mathrm{~W}$ images, and steady-state free precession sequence. A non-enhanced filling defect has been demonstrated after intravenous administration of contrast medium [14-15]. In addition, intracardiac tumor thrombi are usually associated with a few malignant infradiaphragmatic tumors, such as renal cells and hepatocellular carcinomas [16]. Tumor thrombi can extend into the right atrium via the inferior vena cava [17]. Distinguishing intracardiac tumor thrombi from a pure intracardiac thrombus is critically important because these two conditions have different behaviors, management, and prognoses. While tumor thrombi appear on adjacent veins with expanded vessel lumens, their enhancement pattern is similar to that of the primary masses, and pure thrombi show nonenhancements on CT and MRI images [18].

\section{Myxoma}

Myxoma is the most common benign cardiac tumor that tends to occur in middle-aged women and is frequently sporadic. However, Carney syndrome should be considered when patients report multiple myxomas with hyperendocrinopathy and hyperpigmentation [19]. Myxomas are primarily located in the left atrium and are attached to the interatrial septum adjacent to the fossa ovalis. These tumors are typically lobulated, well-defined, and mobile masses with narrow pedicles. They appear as heterogeneous, echogenic masses on TTE and are often heterogeneous and contain calcifications and gelatinous substances with hypoattenuation on CT imaging [20]. Furthermore, myxomas on CMR imaging are isointense on T1W images and hyperintense on T2W images with heterogeneous enhancements following application of contrast materials. Occasionally, T2W images show lower signals due to calcification and hemosiderin [21].

\section{Papillary fibroelastoma}

Papillary fibroelastoma is a rare benign cardiac tumor, prevalence-wise second to myxoma, which usually arises from the valvular endocardium and rarely from the RV [22]. The mass is small, heterogeneous, and mobile, with multiple papillary fronds. Almost half of the tumors are pedunculated, < $3 \mathrm{~mm}$ in size, and prolapse into the cardiac chambers during the cardiac cycle [23]. On echocardiography, a papillary fibroelastoma appears as a hyperechoic mass. On cardiac CT images, the papillary fibroelastomas appear as hypodense masses with non-significant enhancements that are often misdiagnosed due to their small size. Moreover, these tumors frequently appear as intermediate on T1W images and hyperintense on $\mathrm{T} 2 \mathrm{~W}$ images with typically homogeneous enhancements [24].

\section{Lymphangioma}

Cardiac lymphangiomas are rare, benign congenital tumors composed of thin-walled spaces lined by the endothelium. Though lymphangiomas contain lymph, they remain isolated from the lymphatic system [25]. Symptoms related to cardiac lymphangiomas depend on the tumor size and location. These tumors usually occur in the pericardial spaces and are associated with other tumors, such as lymphatic vascular masses and lipomas [26]. On echocardiography, cardiac lymphangiomas appear as ill-defined cystic or echogenic masses with a lack of vascular flow inside the tumor. On CT imaging, cardiac lymphangiomas appear as cystic masses filled with homogeneous material and show low attenuation with no significant enhancements. However, few tumors are inhomogeneous, with solid stromal elements. On MRI, most tumors appear hypointense on $\mathrm{T} 1 \mathrm{~W}$ images and hyperintense on $\mathrm{T} 2 \mathrm{~W}$ images without apparent enhancements. However, tumor signal intensities vary due to the presence of methemoglobin, fat, or proteinaceous material in the lymphatic fluid. Cardiac lymphangiomas exhibit irregular enhancement patterns depending on complex tumor components [27].

\section{Metastasis}

Cardiac metastases are considered in patients with prior cancer and new cardiac complaints, such as obstructive symptoms or arrhythmias. Cardiac metastases occur 30 times more frequently in patients with cancer than in those with primary cardiac tumors. Metastases commonly originate from malignant melanomas, germ cell tumors, and leukemia [28]. There are three main metastatic routes: hematogenous, lymphatic, and direct. The hematogenous route generally spreads to the pericardium, whereas the other two routes commonly spread to the myocardium and endocardium. Metastases are usually asymptomatic, making earlier detection challenging [29]. They appear as isoechoic to hyperechoic lesions on TTE, and calcifications are common. Tumors often demonstrate heterogeneous, isodense enhancements relative to muscle. Cardiac metastases are generally hypointense to isointense on T1W images and isointense to hyperintense on T2W images, exhibiting varying degrees of enhancement after administration of contrast material.

\section{Cardiac echinococcosis}

Cardiac echinococcosis is a rare disease that is endemic in rural regions globally, with an estimated prevalence ranging from $0.5 \%$ to $2 \%$ of all hydatid cases. The right ventricular mass is primarily composed of cystic fluid and is usually asymptomatic; however, patients can have clinical symptoms with cyst enlargement. Echinococcus granulosis is generally located in the left ventricular wall and reaches the heart mainly through the coronary circulation. Approximately $10 \%$ of cardiac cases are involved in RV [30]. On echocardiography, the cysts present as heterogeneous cystic areas without vascular flow, and on CT scans, they appear cystic without enhancement. Few echinococcal cysts have been identified with 
calcifications and solid components. Most of these cysts appear hypointense on T1W images and hyperintense on T2W images without obvious enhancements. Linear structures of variable thickness have been demonstrated as low-intensity signals on T2W images which represent fibrous septa within echinococcal cysts that are enhanced after contrast injections [31-32].

Among the differential diagnoses, cardiac thrombi and metastases can be ruled out with the help of imaging features and clinical histories. Occasionally, a bronchogenic cyst can be misdiagnosed as a teratoma when an RV tumor consists of fatty tissue, mucoid fluid, patchy calcifications, and solid components with moderate enhancements. Based on histopathology, lesions comprising the cystic areas lined by ciliated, pseudostratified columnar epithelium and surrounded by smooth muscle with an intermediate degree of differentiation toward a normal tracheobronchial tree structure are diagnosed as bronchogenic cysts. In contrast, teratomas are haphazardly arranged with no resemblance to a normal tracheobronchial tree [33]. In the present case, the histologic features strongly indicated a bronchogenic cyst ruling out a teratoma.

\section{TEACHING POINT}

Cardiac bronchogenic cysts are rare, benign tumors that are challenging to diagnose because of the atypical associated symptoms and imaging findings. Cardiac CT and CMR are valuable techniques that can demonstrate the components and enhancement patterns of the mass. Irrespective of presence of symptoms, surgical resection is the preferred approach to avoid complications.

\section{REFERENCES}

1. Roos-Hesselink JW, Verhoeven GT, Stoker J. Bronchogenic cyst mimicking an intracardiac mass: diagnosis by magnetic resonance imaging and treatment by needle aspiration. Heart. 1996;75(6):639. PMID:8697173.

2. Wang J, Zhu Q, Liang B, et al. Left Ventricular Bronchogenic Cyst. Ann Thorac Surg. 2016;101(2):744-6. PMID:26777927.

3. Park J, Cho GY, Park KH, et al. Intracardiac bronchogenic cyst: report of a growing lesion. Circulation. 2014;130(13):1107-9. PMID:25245848.

4. Nishida N, Hata $\mathrm{Y}$, Nomoto K. Intramyocardial bronchogenic cyst: histological appearance and a review of the literature. Cardiovasc Pathol. 2017;28:64-7. PMID:28334597.

5. Liu HS, Li SQ, Cao ZL, et al. Clinical Features and Treatment of Bronchogenic Cyst in Adults. Chin Med Sci J. 2009;24(1):60-3. PMID:19382427.

6. Baumann CR, Konu D, Glatzel M, et al. Thoracolumbar intradural extramedullary bronchiogenic cyst. Acta Neurochir (Wien). 2005;147(3):317-9. PMID:15605199.
7. Ma X, Li W, Niu C, et al. Intraspinal bronchogenic cyst: Series of case reports and literature review. J Spinal Cord Med. 2017;40(2):141-6. PMID:28317447.

8. McAdams HP, Kirejczyk WM, Rosado-de-Christenson ML, et al. Bronchogenic Cyst: Imaging Features with Clinical and Histopathologic Correlation. Radiology. 2000;217(2):441-6. PMID:11058643.

9. Li X, Chen Y, Liu J, et al. Cardiac magnetic resonance imaging of primary cardiac tumors. Quant Imaging Med Surg. 2020;10(1):294-313. PMID:31956550.

10. Padovani B, Hofman $\mathrm{P}$, Chanalet $\mathrm{S}$, et al. Intrapericardial bronchogenic cyst: CT and MR demonstration. Eur J Radiol. 1992;15(1):4-6. PMID:1396787.

11. Tsuzuku A, Asano F, Murakami A, et al. Hemothorax with a high carbohydrate antigen 19-9 level caused by a bronchogenic cyst. Intern Med. 2014;53(17):1981-4. PMID:25175134.

12. Ali S, Rauf A, Meng LB, et al. Case Report: Severe back pain, epigastric distress and refractory nausea; an unusual presentation of mediastinal bronchogenic cyst. F1000Res. 2018;7:960. PMID:30345024.

13. Mohan B, Chhabra ST, Gulati A, et al. Clinical and echocardiographic diagnosis, follow up and management of right-sided cardiac thrombi. Indian Heart J. 2013;65(5):529-35. PMID:24206876.

14. Patnaik S, Shah M, Sharma S, et al. A large mass in the right ventricle: Tumor or thrombus? Cleve Clin J Med. 2017;84(7):517-9. PMID:28696199.

15. Leick J, Szardien S, Liebetrau C, et al. Mobile left ventricular thrombus in left ventricular dysfunction: case report and review of literature. Clin Res Cardiol. 2013;102(7):479-84. PMID:23584757.

16. Cuevas C, Raske M, Bush WH, et al. Imaging Primary and Secondary Tumor Thrombus of the Inferior Vena Cava: MultiDetector Computed Tomography and Magnetic Resonance Imaging. Current Problems in Diagnostic Radiology. 2006;35(3):90-101. PMID:16701120.

17. Oltean MA, Matuz R, Sitar-Taut A, et al. Renal Cell Carcinoma With Extensive Tumor Thrombus Into the Inferior Vena Cava and Right Atrium in a 70-Year-Old Man. Am J Mens Health. 2019;13(3):1557988319846404. PMID:31046582.

18. Rohatgi S, Howard SA, Tirumani SH, et al. Multimodality Imaging of Tumour Thrombus. Can Assoc Radiol J. 2015;66(2):121-9. PMID:25660299.

19. Sardar MR, Lahoti A, Khaji A, et al. Recurrent right ventricular cardiac myxoma in a patient with Carney complex: a case report. J Med Case Rep. 2014;8:134. PMID:24886234. 
20. Haji K, Nasis A. Radiological characteristics of atrial myxoma in Cardiac Computed Tomography. J Cardiovasc Comput Tomogr. 2017;11(3):234-6. PMID:28202247.

21. Restrepo CS, Largoza A, Lemos DF, et al. CT and MR imaging findings of benign cardiac tumors. Curr Probl Diagn Radiol. 2005;34(1):12-21. PMID:15644859.

22. Niino T, Unosawa S. Papillary fibroelastoma of the right ventricular free wall. Case Rep Surg. 2014;2014:654641. PMID:25258692.

23. Jain R, Kolli L, Vindhyal SR, et al. Cardiac Mass: A Case of Cardiac Papillary Fibroelastoma. Cureus. 2018;10(10):e3482. PMID:30613444.

24. Han J, Xiang H, Ridley WE, et al. Anemone appearance: Papillary fibroelastoma. J Med Imaging Radiat Oncol. 2018;62 Suppl 1:12. PMID:30309164.

25. Diao W-J, Shi C, Liu G, et al. The diagnosis and treatment of cardiac lymphangioma: A case report and literature review. Medicine. 2019;98(2):e14000. PMID:30633187.

26. Araoz PA, Mulvagh SL, Tazelaar HD, et al. CT and MR imaging of benign primary cardiac neoplasms with echocardiographic correlation. Radiographics. 2000;20(5):1303-19. PMID:10992020.
27. Soler R, Rodriguez E, Remuiñán C, et al. Mediastinal Lymphangioma Involving The Heart: CT and MR Findings. Clinical Radiology. 2002;57(5):415-8. PMID:12014941.

28. Taguchi S. Comprehensive review of the epidemiology and treatments for malignant adult cardiac tumors. Gen Thorac Cardiovasc Surg. 2018;66(5):257-62. PMID:29594875.

29. Kaulen LD, Tietz F, Gradistanac T, et al. Cardiac melanoma metastases as a cause of sudden cardiac death. Clin Res Cardiol. 2019;108(6):716-8. PMID:30535800.

30. Fennira S, Kamoun S, Besbes B, et al. Cardiac hydatid cyst in the interventricular septum: A literature review. International Journal of Infectious Diseases. 2019;88:120-6. PMID:31499211.

31. Ohri S, Sachdeva A, Bhatia M, et al. Cardiac hydatid cyst in left ventricular free wall. Echo Res Pract. 2015;2(1):K17-9. PMID:26693324.

32. Karantanas AH, Bitsios G, Karaiskou E. Echinococcus of the pulmonary artery: CT, MRI and MRA findings. Comput Med Imaging Graph. 2000;24(4):265-7. PMID:10842051.

33. Roma A, Varsegi M, Magi-Galluzzi C, et al. The distinction of bronchogenic cyst from metastatic testicular teratoma: a light microscopic and immunohistochemical study. American Journal of Clinical Pathology. 2008;130(2):265-73. PMID: 18628097

\section{FIGURES}
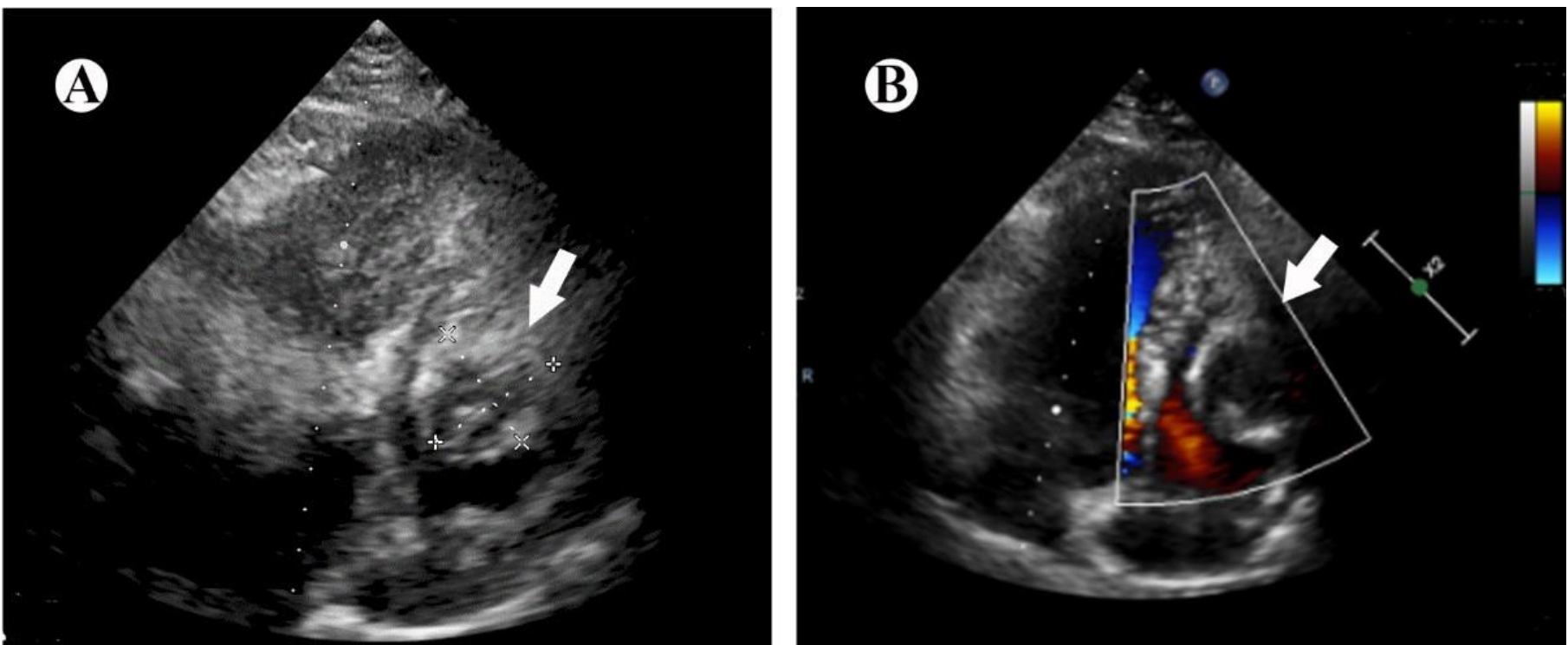

Figure 1: 49-year-old man with an intracardiac bronchogenic cyst

FINDINGS: An apical 4-chamber view demonstrates an oval, right ventricular mass $(3.6 \times 3.3 \mathrm{~cm})$ attached to the free wall of the right ventricle (white arrow). The mass appears to be well-defined, heterogeneous, echogenic without right ventricular outflow tract obstruction. The mass lacks vascularity.

TECHNIQUE: Transthoracic echocardiography (cardiac transducer, 2-dimensional scanning, sector phased 7-12 MHz). A: grey scale, B: color Doppler images. 

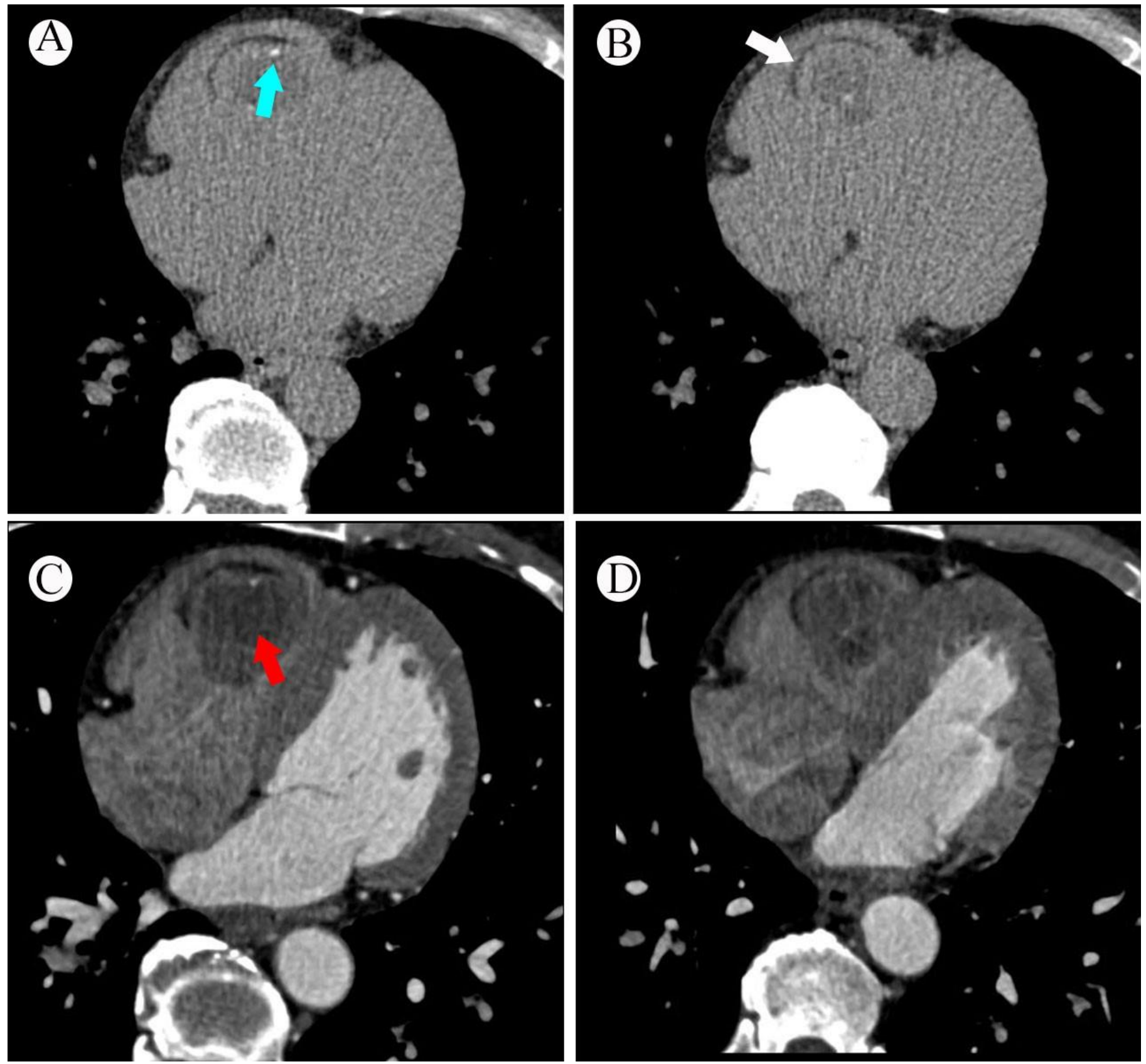

Figure 2: 49-year-old man with an intracardiac bronchogenic cyst

FINDINGS: Axial non-contrast computed tomography (CT) images and axial contrast-enhanced CT in the arterial phase show an oval mass $(3.5 \times 3.4 \times 3.6 \mathrm{~cm})$ attached to the free wall of the right ventricle, and has heterogeneous attenuation. Cystic component attenuation (red arrow) can be observed in the center of the mass when measured 17 Hounsfield units (HU) on non-contrast and 20 HU on contrast-enhanced CT images. The periphery of the mass shows fatty tissue (-50 HU) (white arrow). In addition, scattered punctate calcifications (179 HU) (blue arrow) are also observed in the mass. The soft tissue of the tumor shows moderate enhancement after contrast agent administration.

TECHNIQUE: Chest computed tomography angiography (CTA) performed with Somatom Definition (Siemens Healthcare, Erlangen, Germany) with ECG-gating. A,B: Axial non-contrast CT scan, 120kV, 100mAs, 0.75mm slice thickness, C,D: Axial post-contrast CT, $120 \mathrm{kV}, 380 \mathrm{mAs}, 0.75 \mathrm{~mm}$ slice thickness, Iopromide $370 \mathrm{mg}$ iodine $/ \mathrm{ml}, 72 \mathrm{ml}$ at $5 \mathrm{ml} / \mathrm{s}$. 

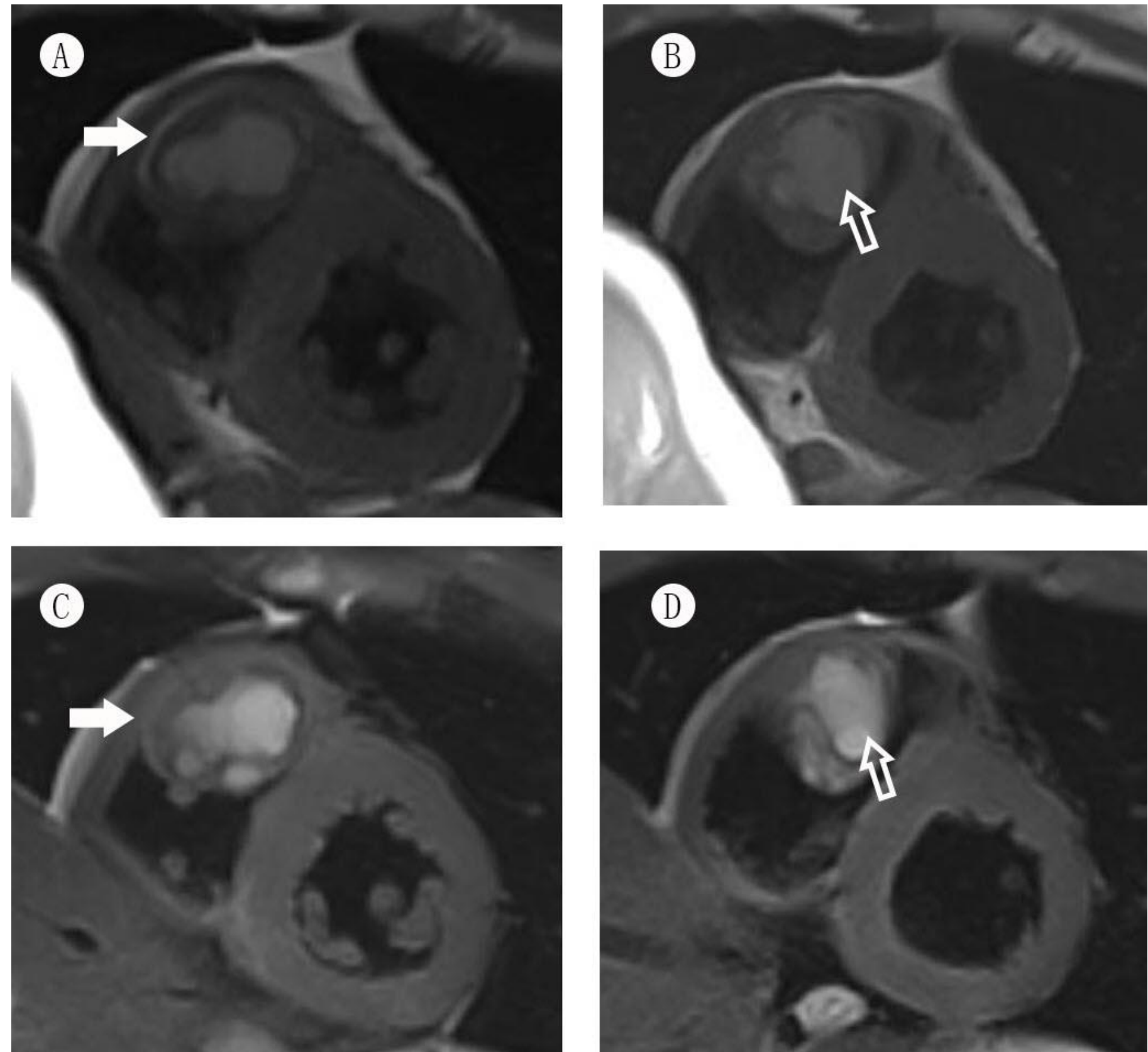

Figure 3: 49-year-old man with an intracardiac bronchogenic cyst

FINDINGS: Cardiac magnetic resonance imaging (MRI) shows a well-defined and heterogeneous mass $(3.4$ x 3.7 x $3.5 \mathrm{~cm})$ with complicated compositions adjacent to the right ventricular free wall. The peripheral fat component demonstrates hyperintense signal on T1-weighted (T1W) images, and lower signal on fat-suppressed T2-weighted (FST2W) images (white arrow). The viscous cystic component demonstrates hyperintense signal on both T1W and FST2W images (white-bordered arrow).

TECHNIQUE: Cardiac magnetic resonance, 3.0 T MR System (MAGNETOM Skyra, Siemens Healthcare, Erlangen, Germany) with breath-holding, short-axis view, before the administration of contrast agent, A,B: T1W images, time to echo (TE) 1.4ms, repetition time (TR) 44.8ms, C,D: FST2W images, TE 1.4ms, TR 44.8ms. 


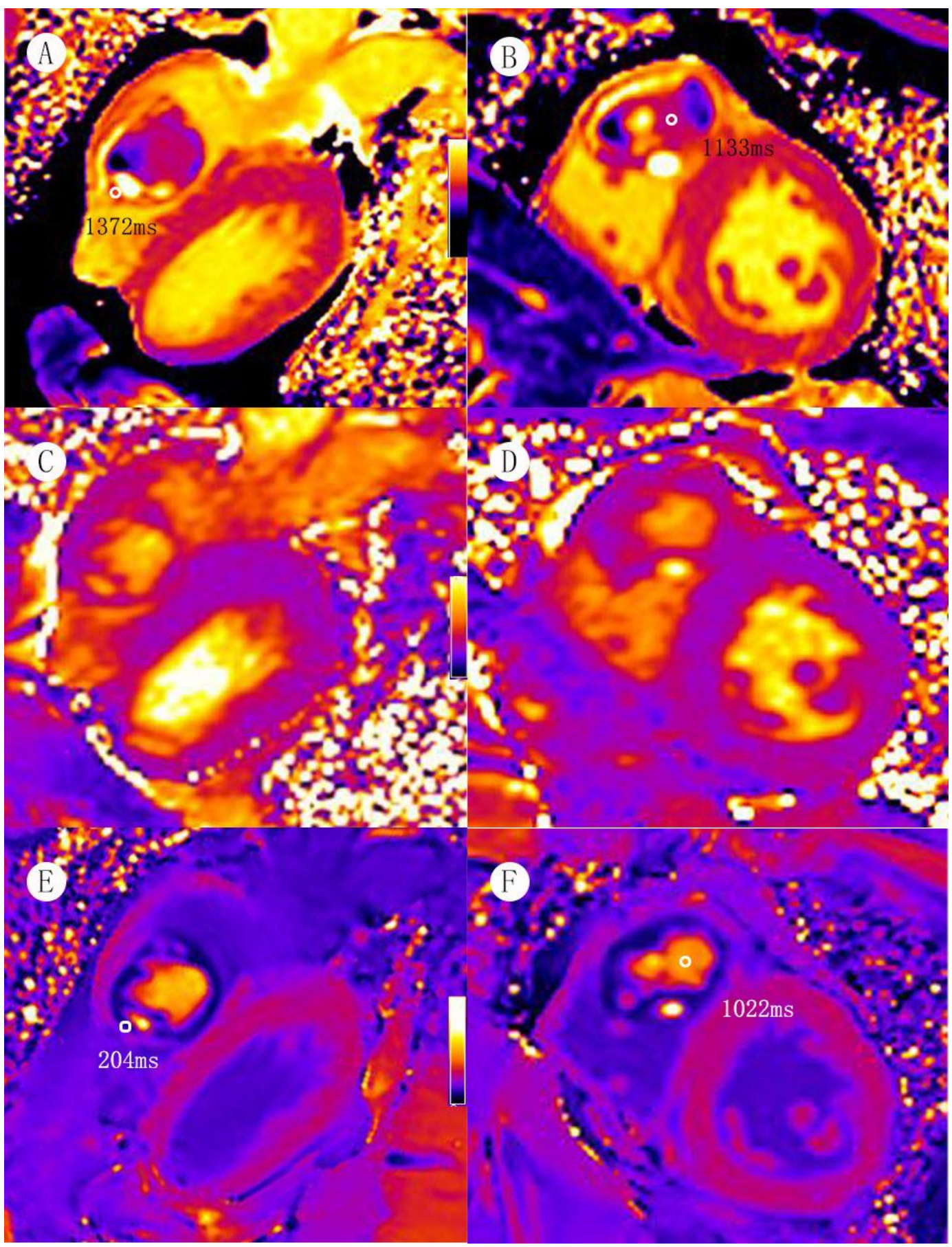

Figure 4: 49-year-old man with an intracardiac bronchogenic cyst

FINDINGS: The peripheral soft tissue of mass shows long T1 (1372ms) and short T2 values (44ms), and the post contrast T1 values $(204 \mathrm{~ms})$ were reduced by $85 \%$. The center cystic component of the mass shows short T1 (1133ms) and long T2 values (80ms), and no obvious drop in T1 values after gadolinium injection (1022ms).

TECHNIQUE: Cardiac magnetic resonance, 3.0 T MR System (MAGNETOM Skyra, Siemens Healthcare, Erlangen, Germany) with breath-holding, long-axis view(A,C,E), short-axis view (B,D,F), A,B: T1 map, time to echo (TE) 1.12ms, repetition time (TR) $286.96 \mathrm{~ms}$, before the administration of contrast agent, C,D: T2 map, TE $1.32 \mathrm{~ms}$, TR $207.39 \mathrm{~ms}$, before the administration of contrast agent, E,F: T1 map, TE $1.12 \mathrm{~ms}$, TR $344.36 \mathrm{~ms}$, after the administration of contrast agent (10 minutes following the administration of $0.4 \mathrm{ml} / \mathrm{kg}$ of gadolinium-based contrast agent). 


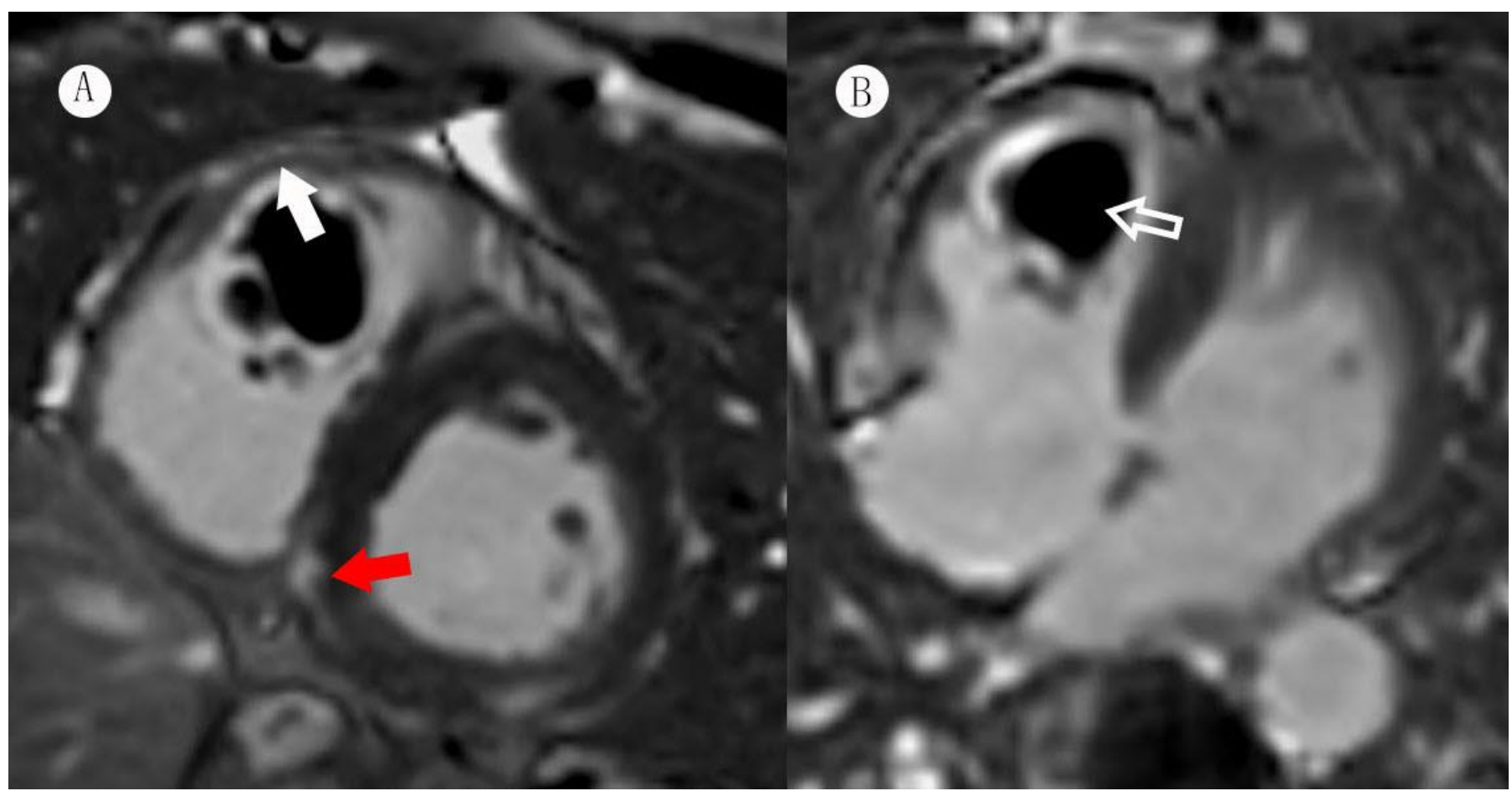

Figure 5: 49-year-old man with an intracardiac bronchogenic cyst

FINDINGS: Cardiac magnetic resonance imaging after the contrast agent was administered, shows prominent peripheral rim enhancement of the right ventricular mass, without fatty (white arrow) and cystic component enhancements (white-bordered arrow). The short-axis view demonstrates slightly delayed enhancement of the inferior insertion site (red arrow).

TECHNIQUE: Cardiac magnetic resonance, 3.0 T MR System (MAGNETOM Skyra, Siemens Healthcare, Erlangen, Germany) with breath-holding, time to echo (TE) $1.24 \mathrm{~ms}$, repetition time (TR) $485 \mathrm{~ms}$, inversion time (TI) $300 \mathrm{~ms}$, late gadolinium enhancement with phase-sensitive inversion recovery sequence (10 minutes following the administration of $0.4 \mathrm{ml} / \mathrm{kg}$ of gadolinium-based contrast agent), A: four-chamber view, B: short axis view.
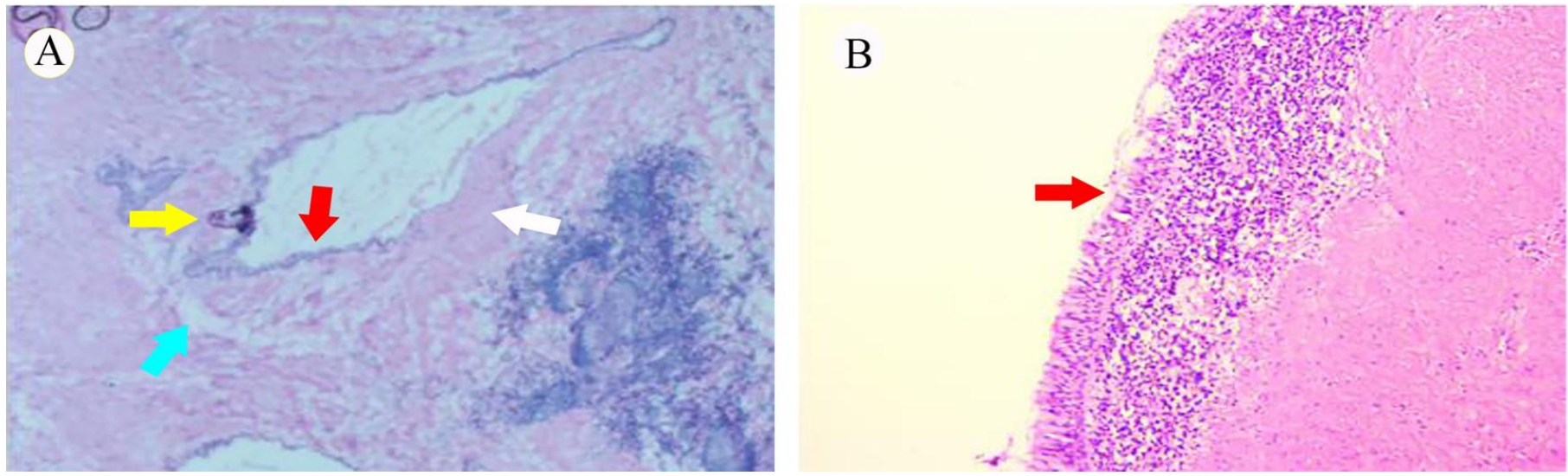

Figure 6: 49-year-old man with an intracardiac bronchogenic cyst

FINDINGS: Photomicrograph of the cyst wall shows a ciliated columnar epithelium with pseudostratification (red arrow), smooth muscle (white arrow), fatty changes (blue arrow), and nodular calcifications (yellow arrow).

TECHNIQUE: Microscopic examination of hematoxylin-eosin stained sections, A: 2X, B: 400X. 


\begin{tabular}{|c|c|}
\hline Etiology & $\begin{array}{l}\text { - Etiology represents abnormal budding of the primitive ventral foregut } \\
\text { - Cardiac primordial tissue is close to the foregut during the early phase of embryonic development }\end{array}$ \\
\hline Incidence & $12 \%$ to $18 \%$ of all primary intracardiac tumors \\
\hline Gender ratio & No predilection \\
\hline Age predilection & None \\
\hline Risk factors & No known \\
\hline Treatment & Surgical resection, whether patients are symptomatic or not \\
\hline Prognosis & Good \\
\hline Findings on imaging & $\begin{array}{l}\text { - Transthoracic echocardiography (TTE): an oval mass with heterogeneous echo in the right ventricle, } \\
\text { without right ventricular outflow tract obstruction. } \\
\text { - Computed tomography (CT): well-defined mass with heterogeneous density attached to the free wall } \\
\text { of the right ventricle. The mass showed cystic changes, fatty tissue, slight calcifications, and soft } \\
\text { tissue with moderate enhancements. } \\
\text { - Magnetic resonance imaging (MRI): a right ventricular mass with complex components, such as } \\
\text { fatty tissue at the tumor periphery, which appeared hyperintense on T1W images and had lower } \\
\text { signals on FST2W images, with long T1 and short T2 values. A cystic component in the middle } \\
\text { showed hyperintense signals on T1W and FST2W images and demonstrated short T1 and long T2 } \\
\text { values. The peripheral zone of the mass showed progressive enhancements in an early phase and } \\
\text { marked enhancements with shortened T1 values in the later phase. }\end{array}$ \\
\hline
\end{tabular}

Table 1: Summary table of cardiac bronchogenic cyst.

\begin{tabular}{|c|c|c|c|c|c|}
\hline & \begin{tabular}{|l|} 
Location \\
\end{tabular} & Morphology & TTE & CT & MRI \\
\hline $\begin{array}{l}\text { Intracardiac } \\
\text { bronchogenic } \\
\text { cyst }\end{array}$ & $\begin{array}{l}\text { Right side of } \\
\text { the heart }\end{array}$ & $\begin{array}{l}\text { Round; } \\
\text { well-defined; } \\
\text { thin wall }\end{array}$ & $\begin{array}{l}\text { Homogeneous, } \\
\text { hypoechoic }\end{array}$ & $\begin{array}{l}\text { Hypodense; } \\
\text { enhanced wall; } \\
\text { calcification; fatty } \\
\text { tissue; mucus }\end{array}$ & $\begin{array}{l}\text { T1: hypointense; T2: } \\
\text { hyperintense; enhanced wall }\end{array}$ \\
\hline Thrombosis & $\begin{array}{l}\text { Left atrium and } \\
\text { auricle; tumor } \\
\text { thrombi mainly } \\
\text { located in the } \\
\text { right atrium }\end{array}$ & $\begin{array}{l}\text { Multiform; poor } \\
\text { mobile }\end{array}$ & Hyperechoic & $\begin{array}{l}\text { Hypodense; no } \\
\text { enhancement; tumor } \\
\text { thrombi with } \\
\text { enhancement }\end{array}$ & $\begin{array}{l}\text { T1, T2, SSFP: } \\
\text { homogeneous hypointense; } \\
\text { no enhancement; tumor } \\
\text { thrombi with enhancement }\end{array}$ \\
\hline Myxoma & Left atrium & $\begin{array}{l}\text { Lobulated; well- } \\
\text { defined; mobile; } \\
\text { a narrow pedicle }\end{array}$ & $\begin{array}{l}\text { Heterogeneous } \\
\text { echo }\end{array}$ & $\begin{array}{l}\text { Heterogeneous } \\
\text { density; } \\
\text { cystic content; } \\
\text { calcification }\end{array}$ & $\begin{array}{l}\text { T1: heterogeneous } \\
\text { intermediate; } \\
\text { T2: heterogeneous } \\
\text { hyperintense; heterogeneous } \\
\text { enhancement }\end{array}$ \\
\hline $\begin{array}{l}\text { Papillary } \\
\text { fibroelastoma }\end{array}$ & $\begin{array}{l}\text { Valvular } \\
\text { endocardium }\end{array}$ & $\begin{array}{l}\text { Small; } \\
\text { pedunculated; } \\
\text { papillary; mobile }\end{array}$ & Hyperechoic & $\begin{array}{l}\text { Hypodense; no } \\
\text { significant } \\
\text { enhancement }\end{array}$ & $\begin{array}{l}\text { T1: intermediate; T2: } \\
\text { hyperintense; } \\
\text { uniform enhancement }\end{array}$ \\
\hline $\begin{array}{l}\text { Cardiac } \\
\text { lymphangioma }\end{array}$ & $\begin{array}{l}\text { pericardial } \\
\text { space }\end{array}$ & Ill-defined & $\begin{array}{l}\text { Heterogeneous } \\
\text { echo; no } \\
\text { vascular flow }\end{array}$ & $\begin{array}{l}\text { Hypodense; no } \\
\text { significant } \\
\text { enhancement }\end{array}$ & $\begin{array}{l}\text { T1: heterogeneous signal } \\
\text { due to complex } \\
\text { components; } \\
\text { T2: hyperintense; } \\
\text { no enhancement or } \\
\text { heterogeneous enhancement }\end{array}$ \\
\hline Metastasis & - & Multilocular & $\begin{array}{l}\text { Isoechoic to } \\
\text { hyperechoic; } \\
\text { calcification }\end{array}$ & $\begin{array}{l}\text { Isodense to } \\
\text { myocardium; } \\
\text { heterogeneous } \\
\text { enhancement }\end{array}$ & $\begin{array}{l}\text { T1: hypointense to } \\
\text { isointense; T2: isointense to } \\
\text { hyperintense; heterogeneous } \\
\text { enhancement }\end{array}$ \\
\hline $\begin{array}{l}\text { Cardiac } \\
\text { echinococcosis }\end{array}$ & $\begin{array}{l}\text { left ventricular } \\
\text { wall }\end{array}$ & $\begin{array}{l}\text { Round; } \\
\text { well-defined; }\end{array}$ & $\begin{array}{l}\text { Homogeneous } \\
\text { hypoechoic; } \\
\text { no flow }\end{array}$ & $\begin{array}{l}\text { Hypodense; no } \\
\text { significant } \\
\text { enhancement; } \\
\text { calcification; solid } \\
\text { component }\end{array}$ & $\begin{array}{l}\text { T1: hypointense; T2: } \\
\text { hyperintense; } \\
\text { fibrous septa with low } \\
\text { signal intensity; } \\
\text { no or slight enhancement }\end{array}$ \\
\hline
\end{tabular}

Table 2: Differential diagnosis table for cardiac bronchogenic cyst. 


\section{ABBREVIATIONS}

$\mathrm{CMR}=$ Cardiac magnetic resonance

$\mathrm{CT}=$ Computed tomography

$\mathrm{CTA}=$ Computed tomography angiography

MRI = Magnetic resonance imaging

TTE $=$ Transthoracic echocardiography

$\mathrm{RV}=$ Right ventricle

$\mathrm{W}=$ Weighted

\section{KEYWORDS}

cardiac tumor; intracardiac bronchogenic cyst; magnetic resonance imaging; computed tomography; transthoracic echocardiography; multimodal imaging

\section{Online access}

This publication is online available at:

www.radiologycases.com/index.php/radiologycases/article/view/4109

\section{Peer discussion}

Discuss this manuscript in our protected discussion forum at: www.radiolopolis.com/forums/JRCR

\section{Interactivity}

This publication is available as an interactive article with scroll, window/level, magnify and more features.

Available online at www.RadiologyCases.com

\section{Published by EduRad}

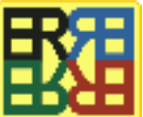

www.EduRad.org 